\title{
PARA INDAGAR CÓMO VIVIR JUNTOS, DEBEMOS PREGUNTAR QUÉ NOS SEPARA: REFLEXIONES EN TORNO AL CONCEPTO DE NECROPOLÍTICA DE ACHILLE MBEMBE
}

\author{
IN ORDER TO THINK HOW CAN WE LIVE TOGETHER, WE \\ MUST ASK WHAT SEPARATES US : \\ REFLEXIONS REGARDING THE CONCEPT OF NECROPOLITICS \\ BY ACHILLE MBEMBE
}

\author{
Dra. Laura Chacon Echeverria \\ Laurachaconecheverría@gmail.com \\ Lic. Carlos Umaña González \\ Carlos.umanagonzalez@ucr.ac.cr
}

Laura Chacón Echeverría: costarricense, psicoanalista, docente catedrática de la Universidad de Costa Rica, Escuela de Psicología, investigadora del Instituto de Investigaciones Sociales, Universidad de Costa Rica. Coordinadora técnica del Programa Casas de Prevención al menor en riesgo psicosocial del Hospital Nacional Psiquiátrico Manuel Antonio Chapuí. Miembro fundador de Lapsus de Toledo. Ha publicado los libros: Maternidad y psicosis (Editorial UCR) y Cuando la feminidad de trastoca en el espejo de la maternidad. Conversaciones con mujeres penalizadas por cometer infanticidio, junto a la Dra. Roxana Hidalgo. Ha publicado numerosos artículos tanto en francés como español, y ha participado como colaboradora en diversos libros relacionados a la temática psicoanalítica.

Carlos Umaña González: costarricense, psicoanalista, docente de la Universidad de Costa Rica, Escuela de Psicología, investigador del Instituto de Investigaciones Sociales, Universidad de Costa Rica. Psicólogo clínico y coordinador del Programa Casas de Prevención Juvenil del Hospital Nacional Psiquiátrico Manuel Antonio Chapuí. Sus últimas publicaciones son: Los modos de subjetivación en el neoliberalismo: la nebulosa de los imperativos, Intimidades y extimidades de la investigación sobre activismos y militancias politicas. Propuestas para el análisis y Tensiones de Sartre a Foucault, subjetividad e historia.

Recibido 30/10/2018 - Aceptado 01/04/2019 


\title{
RESUMEN
}

Partiendo del argumento de Achille Mbembe el cual plantea que existe una lógica política basada en la continuidad de la guerra racial del ayer, sostenemos la pertinencia de una revisión de la propuesta mbembiana para el análisis de la expulsión en los contextos de "desecho mundial". En estos escenarios surge la pregunta por quién toma la decisión de dar vida o dar muerte, respuesta que pasa por los grupos de micropoder: pandillas o maras; que surgen como efecto de las políticas neoliberales. Este artículo pretende desplegar así los elementos que permiten una mayor comprensión del pensamiento mbembiano. Proponemos una profundización en la articulación teórica de la categoría Necropolítica, que entiende la política como trabajo de la muerte, mirando cómo detrás de la política de vida de los Estados modernos y del proyecto de la Ilustración, yace la política de dar muerte.

Palabras clave: necropolítica, enemigo, neoliberalismo, muerte.

\begin{abstract}
Achille Mbembe's issues that the politic of death is the continuity of yesterday's racial war. Starting from this idea, we hold the relevance of reviewing the mbembian proposal for the analysis of exclusion contexts. Is in these scenarios that the question about who makes the decision of giving life or death arises; the answer seems to cross micro-power groups: gangs or maras, which emerge through the neoliberal effect. This article pretends to deploy some of the elements that allow a better comprehension of the mbembian thinking. Through Mbembe's lecture, we propose a deepening of his theorical articulation of Necropolitics that understands politics as a work of death, and invites to see how politics of life in modern states and the Illustration project are in fact politics of death.
\end{abstract}

Key words: Necropolitics, enemy, neoliberalism, death. 


\section{INTRODUCCIÓN}

Cuerpo haz de mí siempre un ser que se pregunta.

Franz Fanon

El bárbaro es siempre el hombre que invade las fronteras de los Estados, quien choca contra las murallas de las ciudades. A diferencia del salvaje, el bárbaro

no se asienta en un fondo de naturaleza al que pertenece. Solo surge contra un fondo de civilización y choca con él. No entra en la historia al fundar una sociedad, sino al penetrar, incendiar y destruir una civilización.

Michel Foucault

Hace un poco más de una década Achille Mbembe (2006) escribió:

(...) rápidamente el crimen está destruyendo la fábrica moral de las ciudades de Sudáfrica, y se está transformando en la mayor amenaza de la democracia de Sudáfrica, así como la manifestación más prominente de la guerra de clases que es una continuidad de la guerra racial del ayer.

Continuidad de la guerra racial del ayer. Esta argumentación defendida pensando en el otro lado del planeta, África, ese continente que para Latinoamérica es lejano, pero lo que venimos de citar, no es lejano para nuestra realidad y principalmente para los barrios de mayor expulsión psicosocial de los centros urbanos, de Centroamérica, México, Colombia, Brasil. Estas topografías de dolor aquí y allá, tienen en común habitar en la pobreza o en la extrema pobreza, y se han transformado en las últimas décadas, en espacios donde impera la paralegalidad. Y, la decisión de dar vida o dar muerte pasa a manos de grupos de micropoder, pandillas o maras entre otros. El abandono neoliberal, las nuevas modalidades de violencia tal y como se representa en el ascenso del homicidio por aumento del sicariato, las nuevas narrativas contra minorías sexuales y étnicas y las diversas modalidades de defensa de lo sagrado o de lo tradicional, no dejan de confluir en estos establecimientos de exclusión, donde resistencia, sacrificio y necropolítica muestran su rostro día con día.

La lógica necropolítica ${ }^{1}$ que analiza quien muere y quien vive, desarrollada por Achille Mbembe en su artículo bajo el mismo nombre, la consideramos como herramienta teórico conceptual útil para pensar nuestras realidades en los barrios de expulsión psicosocial. Sin embargo, más que describir las dinámicas juvenicidas, jóvenes matándose a jóvenes en la lucha por el territorio en la venta del narcomenudeo, este artículo pretende desplegar los elementos que

1 Este concepto no es un modelo o una teoría, sino una categoría que nace en un momento específico como respuesta a una condición de normalización de la guerra. 
permiten una mayor comprensión de este concepto mbembiano, la necropolítica, para leer así, la lógica contemporánea de la violencia de la inmensa población desecho que habita múltiples regiones principalmente no eurocéntricas.

La reflexión de Achille Mbembe $^{2}$ es desde Suráfrica ${ }^{3}$. Desde su territorio piensa la violencia del poder soberano, en sus diferentes expresiones a nivel mundial. Diríamos con las palabras de Mignolo (1995) que busca la rehabilitación del espacio del topos, para poder restaurar el cronos, deconstruyendo la fórmula cartesiana del yo pienso por tanto soy, al, yo soy donde pienso.

Su eje conductor, su linterna, no es la pregunta por la razón, sino directamente por el interrogante, ¿quién tiene el derecho de dar vida, dar muerte?, y ¿cómo se establece este derecho soberano y cuáles son sus excepciones? Mbembe interroga los contextos de no humanidad, donde la vida se cosifica y pierde todo deseo; donde la muerte pasa a invadir las vidas sin que estas acaben. $\mathrm{Su}$ reflexión emerge en la frontera borrosa entre el suicidio, el sacrificio, la libertad, y la emancipación; atravesando las actuales máquinas de guerra ${ }^{4}$ (Deleuze y Guattari, 2006), que hoy día se concentran en hacer de la guerra un negocio, alquilando soldados (muchos de estos, niños), o los mártires de las bombas humanas. Es un ágil pensador que sabe deslizarse bien entre el cronos y el topos, sin dejar de defender que pensar el espacio es un imperativo de análisis. Es decir, explora siempre la deconstrucción de la dinámica de un espacio

2 Achile Mbembe nacido en Camerún en 1957, emprende el estudio de diversos aspectos de los regímenes autoritarios de su época, llega a París en 1982, estudia historia en La Sorbona,e inicia su escritura política en la revista francesa, Politique africaine. Establecido en Sudáfrica, publica en el año 2000, De Ia postcolonie y pasa a ser investigador la Universidad de Witwatersrand en Johannesburgo. Ha escrito también los siguientes textos: De la postcolonie. Essai sur l'imagination politique dans l'Afrique contemporaine (2000), Sortir de la grande nuit. Essai sur l'Afrique décolonisée (2010) y Critique de la raison nègre (2013) Politiques de l'inimitié (2016).

3 Sudáfrica, país con una de las mayores desigualdades sociales del planeta y que continúa sufriendo violencia racial. El 20\% más rico de la población (casi todos blancos) acapara el $60 \%$ de la riqueza. Mientras que el salario medio anual de un trabajador negro apenas supera los 1.000 euros, el de un blanco se acerca a los 7.000. Un 24\% de los hogares carece de agua corriente y un $20 \%$ de electricidad. Con más de la mitad de los jóvenes en desempleo, los índices de criminalidad son alarmantes: hay un asesinato cada 45 segundos y una violación cada 30 (Rivas y Madorrán, 2010)

$4 \quad$ El concepto máquinas de guerra es dado por Deleuze y Guattari (2006, p.387) y retomado por Mbembe: "Estás máquinas se componen de fracciones de hombres armados que se escinden o se fusionan según su tarea y circunstancia. Organizaciones difusas y polimorfas, las máquinas de guerra se caracterizan por su capacidad para la metamorfosis. Su relación con el espacio es móvil. Algunas veces mantienen relaciones complejas con las formas estatales (que pueden ir de la autonomía a la incorporación). El Estado puede, por sí mismo, transformarse en una máquina de guerra. Puede, por otra parte, apropiarse para sí de una máquina de guerra ya existente, o ayudar a crear una. Las máquinas de guerra funcionan tomando prestado de los ejércitos habituales, aunque incorporan nuevos elementos bien adaptados al principio de segmentación y desterritorialización. Los ejércitos habituales, por su parte, pueden apropiarse fácilmente de ciertas características de las máquinas de guerra” (Mbembe, 2008). 
determinado, de una fragmentación territorial, que, con frecuencia se ubica en una frontera expulsora habitada por el racismo y la pobreza, tales como África, Libia o Palestina o Guantánamo. Espacios donde la muerte se diluye en la vida y la vida desaparece ante la imposibilidad de ser, de crear, de estar.

El concepto necropolítica (Mbembe 2006, p.27-28) quiere decir la política como trabajo de muerte, la política de la vida en la producción de la desechabilidad; concierne a un estado de violencia mundana, a un Estado de excepción (Agamben, 1998) donde la ley internacional y la soberanía de una nación se encuentran ignoradas, en la suspensión de la ley; y domina el uso de la fuerza como ley. Chávez Mac Gregor (2013) escribe que el concepto necropolítica fue creado posterior a los eventos del 11 de setiembre, 2001. A partir de este momento, se convierte en imperioso examinar la construcción pública del enemigo y la justificación de dar muerte a los sospechosos, por tanto enemigos. Este dar muerte solo puede darse en la normativización del Estado de excepción. Chávez Macgregor (2013) cita Mbembe sobre la génesis de este concepto:

El término necropolítica, lo usé, por primera vez, en un artículo que fue publicado en Public Culture, en 2003, una publicación estadounidense. Había escrito el artículo inmediatamente tras el 9/11, mientras los Estados Unidos y sus aliados desencadenaban la guerra contra el terror que luego resultaría en formas renovadas de ocupación militar de tierras lejanas y en su mayoría no-occidentales, así como lo que yo llamaría la "planetarización" de la contra-insurgencia, una técnica que se perfeccionó durante las guerras de resistencia anticoloniales, sobre todo en Vietnam y Argelia. Antes del 9/11 varios académicos y pensadores buscaban nuevos vocabularios e intentaban aprovechar nuevos recursos críticos con el objetivo de dar cuenta de lo que deberíamos llamar "las depredaciones de la globalización neoliberal (p.15).

Sobre la base de estas depredaciones de la globalización neoliberal Mbembe posteriormente escribirá su artículo necropolítica, en el año 2006. Mbembe busca explicar estos territorios de crueldad, sobrepasando dos conceptos que piensan también la exclusión contemporánea: nuda vida de Giorgio Agamben y biopolítica de Michel Foucault. Epistémicamente deconstruye la razón europea, principalmente Hegel, desde la cual se oculta la justificación de dar muerte para alcanzar el bien civilizatorio. Sobre el análisis del mundo contemporáneo y sus modalidades de dar muerte, o encontrar la muerte, -fronteras débiles ambas-, reflexiona sobre la violencia y las políticas de la enemistad, sobre el cómo encontrar un espacio a habitar, en la alteridad más no, en la destrucción. Por tanto, con el fin de profundizar el concepto necropolítica, propone una discusión entre tres ejes teóricos: (i) los teóricos anticoloniales (Fanon, Cesaire, 
Seghor) y postcoloniales 5 (ii) la deconstrucción de la razón moderna desde la filosofía hegeliana junto con (iii) los filósofos de la Otredad (Levinas Sartre, Merleau Ponty, Lacan, Foucault, Agamben, Derrida, Deleuze y Guattari). En las páginas siguientes abordaremos desde una vía sintética, estos tres ejes con el diálogo con cuatro autores: Hegel, Fanon, Foucault y Agamben. Y en las consideraciones finales examinaremos la posición mbembiana sobre qué hacer con el enemigo.

\section{DESNUDAR LA RAZÓN EUROPEA Y LA INFLUENCIA POSTCOLONIAL}

\section{Hegel y los monstruos de la razón \\ El hombre aparece por primera vez en el mundo natural, al aceptar voluntaria- mente el peligro de la muerte en una lucha por puro prestigio.}

Hegel, Fenomenología del espíritu

Los monstruos de la razón fueron vistos y pintados con toda genialidad por Francisco Goya, testimonio de su época. Es en los mismos cimientos de la razón, cuando la duda cartesiana es llevada a la calle y la burguesía toma el poder a través del regicidio. La Revolución francesa había puesto en duda la asignación divina del poder, y el ser humano a través de su potencial revolucionario podía transformar los destinos de la humanidad. Sin embargo, se preserva intacta la argumentación de que el progreso de la civilización sólo sería posible efectuando la guerra contra las razas inferiores. Por ende, habita una violencia inherente en el concepto de razón. La muerte de muchos es condición necesaria para sostener y nutrir el movimiento progresivo de la civilización.

$5 \quad$ El pensamiento poscolonial surge en la mitad del siglo XX en el marco de las experiencias de luchas anticoloniales en Asia y África, su común denominador es la lucha por la propia independencia y la deconstrucción de la epistemología europea, dando un lugar a los sin voz, y sin poder (Fanón, 2011; Césaire, 1972; Seghor, 1993). Este pensamiento encuentra su desarrollo y fortalecimiento en la lengua inglesa, desde África, India, Gran Bretaña, Australia y los Estados Unidos (Gigena, 2011). Entre sus precursores se encuentra el filósofo palestino Edward Said (1978), escritor del libro Orientalismo, donde critica la doxa marxista, el proyecto colonial no se reduce a un simple dispositivo económico militar sino en la deconstrucción de la infraestructura discursiva, de los aparatos del saber, dado que la violencia es tanto epistémica, como física. Desde esta misma línea, Ashis Nandy (1983), en The Intimate Enemy, propone que el colonialismo es sobre todo una problemática psíquica, y por ende es insuficiente la lucha material. Nandy lleva a Fanon a la India e introduce el psicoanálisis de la teoría crítica de la escuela de Frankfurt. Cabe a su vez destacar los textos de Gilroy $(1995,2004)$ sobre África, en los cuales defiende el análisis cultural para interrogar la violencia epistémica y física del racismo, para penetrar las barreras de la subjetividad. 
Con la razón moderna el universalismo se transformó en ética, la identidad en raza y la biología en esencias inamovibles. Fraternidad, libertad e igualdad fueron válidas para el hombre blanco y para la alteridad fenotípica, fue lícita una condición no humana. La razón moderna defiende la superioridad biológica y patriarcal del hombre blanco con "una" superioridad teológica, el dios cristiano, sustituido en razón; con "una" geografía, la europea; y "una" epistemología, también la europea, como único locus admitido en la producción de saber ${ }^{6}$. Defensa por tanto de la administración de la muerte en nombre del supremo bien civilizatorio. La razón hace morir en nombre de la civilización, la democratización y el orden.

En este pensamiento moderno y civilizatorio, Mbembe (2006) destaca la filosofía de Hegel, con su tesis propia de la Fenomenología del espíritu (2006 [1807]): la historia camina hacia la civilización; esto es posible porque el hombre toma la decisión de arriesgar su vida ante la muerte, solo así se caminará hacia un mejor estar:

Pero la vida del espíritu no es la vida que se espanta ante la muerte y se mantiene ajena [se preserva] de la desolación, sino la que sabe afrontarla y mantenerse en ella. El espíritu sólo conquista su verdad cuando es capaz de encontrarse a sí mismo en el desgarramiento absoluto (Hegel, cit. en Mbembe 2006a).

En la modernidad este pensamiento hegeliano de un Telos de la historia, pertenece a la gran mayoría de los pensadores europeos, propios del antes y después de la Revolución francesa, entre otros, los filósofos de la Ilustración, Kant y Marx ${ }^{7}$. La razón la podemos pensar desde una teología política, la exigencia del sacrificio como medio para hacer progresar la humanidad, hombre es quien pone en

6 Y la producción de saber de la colonialidad es descalificada como folclore, mitos, leyendas, magia, brujería tradiciones.

$7 \quad$ Esta lógica situacional del sujeto moderno, construyó una subjetividad que podría entenderse a partir de una estratificación de primer y segundo tipo, correspondiendo el primero a los habitantes europeos y norteamericanos, y el segundo, al resto de la periferia conquistada por el proyecto moderno industrial de este continente. Esta condición de barbarizar al otro periférico, se puede leer incluso en autores que plantearon lógicas emancipatorias a la propia modernidad, como el caso de Marx, para quien la dominación burguesa sobre pueblos bárbaros y semi-bárbaros, constituía un avance en lectura secuencial de la historia ya que esta forma de conquista desplazaba al feudalismo. De tal forma, durante los siglos de potenciación de la modernidad se trazaron modalidades políticas diferenciadas para las metrópolis europeas y las periferias que desde ahí se colonizaban, esto, en una misma franja temporal. Así, mientras la lucha contra la potestad eclesiástica tomaba fuerza junto a las disertaciones filosóficas por los derechos individuales en Inglaterra, América, África y algunos espacios de Asia, vivían la cara inversa del proyecto moderno, siendo sometidos a la esclavitud, el dominio y la culturalización colonialista. Esta situación de subyugación implicó un aumento en la precisión de manufactura de instrumentos para el dominio, iniciando una carrera por la tecnificación de la muerte que devendría en enfrentamientos bélicos a gran escala siglos después. 
riesgo su vida. La concepción hegeliana defiende que el progreso de la historia se inscribe gracias a la muerte de los hombres que entregan su cuerpo para un mundo mejor, y la evolución es una línea progresiva de la infancia a la adultez, (en suposición de una evolución hacia la mejoría). Esta historia de la razón europea se confunde con la historia del enemigo. Enemigo es quien no razona con la razón moderna y para que la civilización progrese este debe ser expulsado, exterminado o sometido. La esclavitud es necesaria para el avance de la civilización y este sometimiento cubre la operación de matar al sujeto humano, matar su deseo pero sostenerlo en vida como objeto de producción y utilidad. Es así como, el Estado moderno y con este, el nacimiento del capitalismo, ha defendido la normalización de la construcción de vidas desechables. Destrucción material de los cuerpos y de poblaciones humanas.

Para deconstruir esta razón moderna, la razón como triunfadora de una ética de existencia, Mbembe (2006) se apoya principalmente en la citada filosofía hegeliana, y desde esta realiza la pregunta sobre la soberanía: ¿Quién decide la muerte o la vida de un sujeto, de una población? ¿Cuándo matar y cuándo dejar vivir en los Estados modernos? Consecuentemente, Mbembe nos invita a mirar las relaciones humanas en el cómo, detrás de la política de vida de los Estados modernos, yace la política de dar muerte. De la biopolítica a la necropolítica.

El devenir del hombre y de la historia son posibles sobre la base de la puesta en riesgo de la propia vida, dar la vida para la continuación del Telos de la historia, solo esta entrega permitirá el alcance de un mundo mejor. Y este progreso depende del trabajo de muerte de esclavo. Mbembe introduce la filosofía de Hegel del amo y el esclavo, como vía de sumergimiento a las raíces del pensamiento moderno.

Si el ser humano sólo se engendra en y por la lucha que culmina en la relación entre Amo y Esclavo, la realización y la revelación progresivas de ese ser no pueden tampoco ellas efectuarse sino en función de esa relación social fundamental. (Kojève 1982, p.8 ).

Hegel como pensador de su época tiene 19 años cuando estalla la Revolución Francesa y solo habían pasado 12 años de esta sangrienta revolución con la guillotina sin límite de Robespierre, cuando Napoleón en 1794 vuelve a restituir la esclavitud en Francia, por supuesto la esclavitud de los no blancos. El amo es quien venció al esclavo, el esclavo es el perdedor, y sobre esta lógica, la justificación de la puesta en marcha del poder de un hombre sobre el otro. Justificación de la esclavitud y del maltrato indígena. Citamos a Mbembe: "No se podría comprender en lo más mínimo la evolución de las estructuras jurídicas, filosóficas, narrativas de Europa sin tomar en cuenta la trata de esclavos." (Mbembe, 2010b, p.27). 
Indagar a Hegel sobre la justificación de la administración de dar muerte, es desnudar la razón en su aspecto necropolítico. En el reverso de la luz de la razón se encuentra la sombra de la esclavitud. Alumbrar esta sombra para Mbembe es posible, dejando a un lado la pregunta por la razón e interrogar quién se otorga el derecho de matar, quién el de hacer vivir. La pregunta tiene su respuesta en la construcción de Otro inferior, edificación de un poder y representación de una superioridad-inferioridad que define el sujeto Occidental y el no Occidental. Las colonias africanas y americanas desde su sufrimiento en los siglos el XV y XVI, forman parte central del capitalismo emergente, y rápidamente se transforman en un territorio necropolítico; más sobre la base de decidir quién muere, que decidir la vida, más sobre la base de que justo la ausencia de ley era lo que hacia la ley (Mbembe, 2016).

La intención del sujeto de Occidente fue transformar el sujeto africano en un bárbaro, sujeto de la alteridad desde la incompletud, y lanzando un enunciado de sujeto humano completo, el sujeto de Occidente. Por su parte, el sujeto africano para resistir la sumisión, debe resistir a los discursos de su colonizador que lo coloca como sujeto de la alteridad. Coincidimos con Žižek (2005), el fundamentalismo es la eliminación del Otro, y la base de la constitución del sujeto de Occidente se realiza desde una ontología de expulsión del Otro. Para lograr esta expulsión se identifica al sujeto africano como sujeto obsoleto, es decir, propio del ámbito de la incompletud, y ésta representada como inferioridad.

El capitalismo florece gracias a la trata de esclavos que circula de una manera triangular entre Europa, África y América. Las plantaciones agrícolas producidas por los esclavos, en palabras de Mbembe (2006a), fue el principal laboratorio donde los experimentos fueron conducidos, para que imperase el territorio de la necropolítica y no de una humanidad compartida. El ejercicio del poder en las plantaciones agrícolas ${ }^{8}$ fue una lógica de guerra en tiempos de "paz", admitiendo toda lógica y economía de la tortura, decidiendo una clara política de hacer doler el cuerpo del otro, sin dejar por fuera la lógica del espectáculo como demostración disciplinaria (Mbembe 2001, 2006a).

8 En tanto que estructura política-jurídica, la plantación es, sin ninguna duda, el espacio en el que el esclavo pertenece al amo. La lógica de esclavitud es la significación de la vida como desechable o superflua y allí se implanta una política de muerte: "La condición del esclavo es, por tanto, el resultado de una triple pérdida: pérdida de un hogar, pérdida de los derechos sobre su cuerpo y pérdida de su estatus político. Esta triple pérdida equivale a una dominación absoluta, a una alienación desde el nacimiento y a una muerte social (Mbembe, 2006 ${ }^{\mathrm{a}}$, p.18). 


\section{FRANZ FANON: DESDOBLAMIENTO ABSOLUTO EN EL EN- CUENTRO CON EL OTRO}

Esta episteme racista fue ampliamente cuestionada por Franz Fanon, psiquiatra argelino escritor de Piel negra máscaras blancas ([1952] 2008) y del libro Los condenados de la tierra (2007 [1961]). Desde el pensamiento postcolonial, Mbembe (2011) rescata con fuerza a Fanon, autor prohibido durante su formación universitaria. En una entrevista realizada a la Revista Le Point en el 2011, cuenta que si bien podía leer a Césaire o a Balzac o a Sartre los libros intocables eran los de Fanon:

Es Fanon más que ningún otro quien da cuenta sobre esta especie de fuerza necropolítica, la cual transitando por la ficción, se transforma en una enfermedad de la vida, es decir, en un acto de reversión permanente, toma la muerte por la vida y la vida por la muerte". (...) Leer Fanon actualmente quiere decir trasladar en palabras de nuestro tiempo las preguntas más importantes que lo forzaron a sostenerse de pie, romper con sus propias raíces e irse a caminar con otros, compañeros de una nueva ruta que los colonizados debían de trazas por sus propios medios, con su propia creatividad y con su voluntad indomable (Mbembe 2011, p.2).

Este psiquiatra, psicoanalista argelino, participó activamente en la Guerra de Argelia ${ }^{9}$ contra Francia para la recuperación de su territorialidad. Su activismo político le permitió desvestir la razón Occidental, denunciando cómo la ética del mal cae siempre sobre el no blanco y la del bien sobre el blanco. Como psicoanalista no olvida que la violencia se introduce en los cuerpos para manifestarse en las dificultades de construcción de vínculos sociales alejados de la destrucción; Fanon cuenta la historia de un niño argelino que mata a su compañero porque este es europeo, o la del torturador que no agota su violencia dentro de su trabajo y la extiende hasta torturar con profunda violencia a su familia.

El análisis que vamos a emprender es psicológico. No obstante, para nosotros sigue siendo evidente que la verdadera desalienación del negro implica una toma de conciencia abrupta de las realidades económicas y sociales. Si hay complejo de inferioridad, éste se produce tras un doble proceso: económico, en primer lugar; por interiorización, o mejor dicho, por epidermización de esta inferioridad, después ([1952] 2008, p. 44).

9 Cuya independencia fue alcanzada en 1959, no logrando Franz Fanon más que dos años más. Muere de leucemia en 1961. 
El objetivo de Fanon fue el descubrir, analizar y antagonizar las trayectorias en que el sujeto africano se "epidermiza" y se somete al poder, y cómo con el reconocimiento de su piel negra, puede resistir los procesos de subjetivación ${ }^{10}$. La libertad para Fanon debe también entenderse como cura. Fanon es uno de los primeros en hablar de una filosofía de cuido. La herida que deja el blanco, el daño psíquico que ha dejado esta relación negro blanco debe conocerse para poder luchar hacia la propia reparación, que es simultáneamente la liberación de su cuerpo y la de sus territorios colonizados. La política de la violencia no debe ser visualizada en término de síntomas, al contrario debe ser comprendida desde una genealogía de constitución compleja. El poder está en la edificación de los cuerpos, y el juego entre sometedor-sometido, amo y esclavo no puede cortarse más que con la liberación de los territorios. La cura psíquica para Fanon es también una cura social y espacial. Sin esta liberación no podrá detenerse una razón que defiende la exterminación del Otro inferior, derecho del soberano que sin ley y sin justicia es propietario de la decisión de mantener con vida o dar la muerte en las plantaciones agrícolas.

Fanon no cree en el pacifismo, el pacifismo no puede luchar para finalizar la sujeción Si bien, Mbembe dice sentirse más cerca de una lucha donde la violencia sea la última respuesta, cree absolutamente relevante para el tiempo contemporáneo continuar fortaleciendo las preguntas de Fanon sobre la sujeción del sujeto africano, porque la historia de la colonia no está en el pasado del sujeto africano, se encuentra en su edificación psíquica actual. Y en el sujeto negro, toda la condición humana se coloca como interrogante. Desdoblamiento absoluto en el encuentro con el Otro.

\section{MÁS ALLÁ DE MICHEL FOUCAULT Y GIORGIO AGAMBEN}

El objetivo de Mbembe es examinar el paradigma de las poblaciones desechables y desde este, analizar el sadismo y el exceso anudados a las tecnologías de destrucción; y asimismo, el cómo la humanidad negra quedó negada en términos absolutos como humanidad. Para este objetivo, el filósofo camerunés considera insuficiente el agudo análisis sobre la biopolítica de Michel Foucault, o el importante concepto teórico, nuda vida de Giorgio Agamben, inspirado en los escritos de Hannah Arendt sobre los campos de concentración. A continuación, los planteamientos mbembianos en torno a estos dos conceptos.

10 Judith Butler, en Los sentidos del sujeto, libro focalizado en reflexionar cuerpo y violencia con base a los aportes Franz Fanon y Jean-Paul Sartre; define sujección (1997, p. 2) como el proceso de subordinarse al poder en la simultaneidad de devenir sujeto. El sujeto Occidental es el sujeto amo, que domina el Otro incompleto, es quien categoriza identifica, resuelve nombra, establece su propia ley, concepciones que llevan a la visión del sujeto blanco como quien no está en falta y el no blanco como sujeto en falta, representante de la figura de lo negativo. 


\section{Foucault: Anotaciones en torno a la raza como producción de biopoder}

Empecemos por Foucault (1979) y su concepto de biopolítica, creado en los años setentas, para dar cuenta de la tecnología de poder que denomina las políticas de la vida. Con la gestación de los Estados modernos nace el discurso de la responsabilidad estatal en torno al cuido de la salud de sus habitantes, lo biológico y lo demográfico pasan a ser contemplados como recursos importantes de fortalecimiento de los Estados. En otras palabras, el control, la distribución y la determinación de la vida se genera desde clasificaciones biológicas, las cuales pasan a ser las formas de regulación (salud, higiene, natalidad, longevidad, raza). Los lentes de lo científico profundizan hacia el conocimiento del cuerpo para extender los años de vida, pasando así a renovarse permanentemente dos tecnologías disciplinarias, la anatomopolítica y el biopoder. Foucault defiende así que el poder es positivo, productivo, y no necesariamente coercitivo. El poder es un hacer vivir ${ }^{11}$. El soberano ya no decide quién muere y quién vive sino, el Estado moderno transforma la lógica de este orden en quién vive y quién muere, en administración de una lógica gubernamental. Es decir, la soberanía se configura como una lógica del poder de muerte que se conforma desde una regulación de la vida biológica de la población por parte del Estado. ¿Cómo entender entonces el ejercicio interrumpido del derecho a matar ejercido bajo el arbitrio del biopoder?

Para Foucault (1996), la raza es el fundamento de la producción del biopoder, la forma moderna de poder, pues permite explicar la "aparente" paradoja de un poder que se ejerce sobre la vida promoviendo, al mismo tiempo, aquello que la anula: una multiplicidad de muertes. Para el autor el racismo ${ }^{12}$ moderno es estatal y biologizante:

En líneas generales, creo que el racismo atiende a la función de muerte en la economía del biopoder, de acuerdo con el principio de que la muerte de los otros significa el fortalecimiento biológico de uno mismo en tanto miembro de una raza o población (Foucault, 2002a, p.232-233).

$11 \quad$ Foucault distingue tres niveles de generalidad en el ejercicio del poder: un nivel microfísico en el que operarían las tecnologías disciplinarias y de producción de sujetos, así como las «tecnologías del yo» que buscan una producción autónoma de la subjetividad; un nivel mesofísico en el que se inscribe la gubernamentalidad del Estado moderno y su control sobre las poblaciones a través de la biopolítica; y un nivel macrofísico en el que se ubican los dispositivos supraestatales de seguridad que favorecen la «libre competencia» entre los Estados hegemónicos por los recursos naturales y humanos del planeta (Foucault, 1979).

12 En la introducción de Foucault (2002b) a la Historia de la Sexualidad, el racismo aparece en el siglo XIX como una forma de retroversión que Foucault termina renegando [...] la gran ironía histórica de la modernidad es que la aniquilación hitleriana de los judíos haya sido llevada a cabo en nombre de los signos arcaicos, premodernos, de la raza y la sangre [...] más que por la política de la sexualidad. 
Los postcolonistas (Spivak, Nandy) discuten con Foucault sobre cuando se inicia el ejercicio del poder de la guerra de las razas, Foucault (1996a) no reconoce la influencia colonial en la praxis racista y además ubica esta guerra más cerca del siglo XIX, no justo en el momento de inicio de las colonias siglo XV. Al respecto leemos a Castro-Gómez (2007):

Lo que parece querer decir Foucault es que las colonias fueron uno de los laboratorios en los que se probó el racismo en tanto que dispositivo biopolítico de guerra. No está diciendo que el racismo nace con el colonialismo, ni que el colonialismo es la condición de posibilidad del racismo; lo que dice es que la experiencia colonial europea coadyuva a desarrollar el discurso del racismo (p.158).

Mbembe le discute a Foucault ${ }^{13}$ que la biopolítica somete la vida al tamiz científico y sobre todo a la verdad estadística, pero no alcanza en explicar las políticas de muerte en múltiples territorios, desde el surgimiento de las colonias y la legitimación dentro de estas del poder de matar. Justo por esta limitación de Foucault (1979b), en su concepto de biopolítica como productor de vida y no visualizar la excepción de la contraparte, la colonia, es que Mbembe crea el concepto necropolítica, defendiendo que es el racismo, el eje desarrollador de esta condición de establecimiento del Otro desechable y por tanto, la puesta en marcha de la necropolítica, desde el genocidio colonizador.

Pasemos ahora a la discusión del concepto nuda vida, de Agamben construido para explicar la política de terror y muerte contra otras poblaciones.

\section{Agamben y de cómo el homo sacer se encuentra también en las plantaciones de esclavos}

Hannah Arendt, filósofa expulsada de la Alemania Nazi por su condición de judía, dedica gran parte de su vida a analizar aquellos que como su caso, quedan en condiciones de no protección legal; por ejemplo, los judíos que antes de ser enviados a los campos de concentración habían ya sido destruidos como personas jurídicas.

Agamben (1998) toma de su libro, Los orígenes del totalitarismo y principalmente del capítulo: Las perplejidades de los derechos del hombre, para crear el concepto

13 Así como Butler lo desarrolla, devenir sujeto se encuentra entrelazado a las condiciones de poder, el poder es instancia externa y asimismo es instancia interna, es decir, la base en que el sujeto se asume y se localiza a sí mismo. Esta constitución del sujeto se da a través de la resistencia, la agencia, la complicidad y la ambivalencia en relación al poder que le es externa, pero asimismo es interiorizado (Butler 1997, p.13). El sujeto no puede ser comprendido fuera del dominio del poder. 
Homo Sacer, refiriéndose al sujeto que no se encuentra ni fuera ni dentro de la ley, pero sí incluido desde su expulsión. El Homo Sacer, revestido por una nuda vida ${ }^{14}$, es aquel que se le puede torturar, matar incluso sin que este acto sea denominado, homicidio. Si bien Agamben (1998) admira el trabajo de Arendt, formula en su libro Homo Sacer que a Arendt le falta en el trabajo de todo aquel que queda fuera de la protección de la ley el análisis biopolítico $(1998$, p.4) ¿Qué es la política?, se pregunta Agamben. Si esta reside fundamentalmente en el acto de la exclusión, de la vida nuda, y el elemento excluido es consubstancial al espacio de la polis misma; ¿cómo el elemento expulsado es incluido por medio de su expulsión?

Agamben (1998) se sitúa más en una dirección diferenciadora, preguntándose por las excepciones que devienen norma, que conllevan a la suspensión de la ley y al uso de la violencia hacia quienes se localicen en los márgenes del poder. Es decir, el nudo sustancial es la aparición de la vida nuda como correlato de la soberanía. Una de las conclusiones más importantes de Agamben (1998) es que no es la ciudad sino el campo de concentración lo que deviene el paradigma más relevante de la biopolítica, por medio del trato al Homo Sacer (Agamben, 1998, p.181), en la construcción de nuevas geografías de terror que hablan de nosotros, los que habitamos fuera del campo de concentración.

Mbembe (1996a) le discute a Agamben (1998) que el paradigma de la biopolítica, nuda vida, no es más relevante en la Europa central de los campos de concentración, que en las plantaciones agrícolas de los esclavos en África y América. El Homo Sacer se encuentra en las plantaciones agrícolas del siglo XV en adelante. En las plantaciones sostenidas por los esclavos nació el racismo, y de ahí su discusión con Foucault sobre la guerra de las razas (su nacimiento en el siglo XIX). El paradigma biopolítico por excelencia, son los territorios trabajados por los esclavos, y aquí su discusión con Agamben.

El modelo de la colonia contemporánea es Palestina, desde la lectura de Mbembe. Territorio de espacios controlados y en asedio; donde el aislamiento, la separación, la imposibilidad de movimiento y la burocratización de las fronteras se organizan bajo un esquema sin lógica ni legalidad. Esta condición de excepción, garantiza el control del territorio y el aniquilamiento de la población. En su texto Necropolítica, Mbembe ofrece dos ejemplos de violencia extrema provenientes de nuestra contemporaneidad. Los bombas suicidas donde su emancipación, su libertad y su gloria se encuentra transformando su cuerpo en un arma y destruyendo y destruyéndose para un nuevo comenzar, la vida eterna en el más allá. Para devenir he de morir, una forma de ser a partir de la muerte. El futuro se

14 Concepto creado por Walter Benjamín (Benjamín, 2002, p.242). y luego retomado por Agamben. El concepto vida nuda refiere a una vida que no existe, los que está situado solo desde lo biológico pero ha perdido todo su poder de decisión, es decir de vida. 
alcanza a través de la muerte y no de la vida, al menos no esta vida que es con un cuerpo. El deseo de alcanzar la eternidad (Mbembe 2006, p.37), puede bien ser el norte que guía a estos mártires y al empuje de la muerte por sus familias. La muerte del sí mismo, por sí mismo, es el acto de sacrificio que será premiado con la libertad de una vida después de la muerte. Aquí la muerte está vaciada de un significado de finitud, es solo un puente a un comienzo de un estar, mejor.

Las máquinas de guerra, que se han transformado principalmente en África en el alquiler de soldados y ejércitos privados que matan como profesionales no por ninguna convicción, ningún motivo más que el dinero; los niños soldados como ejemplo máximo del no respeto a la vida como potencia de desarrollo, el uso de la infancia en su estado de vulnerabilidad para ganar dinero matando; y aquí lo teleológico no tiene ningún sentido al igual que estar vivo, o tener alguna protección en la polis. Solo espacios de crueldad sin sentido alguno y el enemigo aquí es solo a quien matar por el pago a recibir.

\section{CONSIDERACIONES FINALES: EL AÚN ES UNA FUERZA VIVA DE INSPIRACIÓN 15}

En estas consideraciones, posterior a la deconstrucción de la razón moderna como necropolítica desde el pensamiento de Mbembe, con apoyo principalmente de cuatro autores, Hegel, Fanon, Foucault y Agamben; queremos cerrar con la pregunta a Mbembe en esta necropolítica humana, ¿qué hacer? El autor sostiene la apuesta por creación de mundos diferentes que no sean topografías de crueldad, no sin mirar el atrás, no sin mirar el presente. La deconstrucción de sentido es un reto en la lógica de la violencia contemporánea. La desaparición del derecho y el dominio de la violencia y la excepción como justificación soberana, conlleva a Mbembe a pensar la categoría del enemigo. Con dolor asegura: el enemigo ya no es el colono, hoy día, la enemistad se ha establecido entre hermanos (Mbembe 2016 p.9). El enemigo no es solo una categoría ontológica, que expresa las relaciones existentes, es también teológica. Por principio el enemigo es siempre el enemigo de Dios, y el odio que le siento, es el odio que Dios siente.

Y en este pensar la reinvención, Mbembe (2016c) habla del deseo, ese movimiento que permite el caminar, el encuentro con el objeto, ese movimiento, esa pulsión, esa edificación fantasmática que hace del sujeto una singularidad, debe también ser deconstruido para entender la fantasmática de la persecución y de la omnipotencia del placer del exceso y del goce sádico. Deconstruir el deseo del amo, su persecución frente a la alteridad, su miedo ante esta. Deconstruir la

15 Palabras de Mbembe en entrevista Le Point, 2011. 
paranoia ante lo diferente de los Estados modernos y la construcción ficcional de un enemigo permanente. La ansiedad de aniquilación se encuentra en el centro de todo proyecto de separación de todo aquel enemigo considerado amenazante (Mbembe, 2016c). Es el motor que ubica "zonas embrujadas", "zonas alucinatorias, "sujetos poseídos", o enemigos perseguidores de la destrucción. Esta ansiedad siguiendo la lectura de Mbembe, permite justificar el derecho soberano de dar muerte. El autor nos invita a preguntarnos por el motor en el deseo de un enemigo, por el deseo de un apartheid, de una separación, de un encierro o un muro, todo para restaurar dos vías: protección contra el miedo ficcional o real y ascenso de la omnipotencia.

En torno al concepto del enemigo, el discurso paranoide y el discurso del embrujamiento, dos tipos de razonamientos, que nutren y potencian las manifestaciones violentas, y de igual forma, permite rellenar un vacío prácticamente metafísico. Ambos discursos tienen siempre la necesidad de un enemigo, no importa quién sea, necesidad de un chivo expiatorio o contra alguien que se puede ejercer una violencia sin límites (Mbembe, 2016a). Estos discursos que nacen del miedo y de los prejuicios, se fundan en el deseo de desenmascarar el enemigo potencial, inventando el buen enemigo para descargar toda la violencia contra el otro, no bueno.

¿Qué hacer con el enemigo? La pregunta es filosófica, política, ética y encierra otra pregunta, ¿cuál devenir para la humanidad, como alcanzar su no destrucción en la repetición de un motor de muerte? ¿Es la venganza de la sangre contra la sangre la respuesta? ¿Cómo reinventarse? Mbembe (2008) señala que es difícil reinventar algo si uno simplemente repite contra los otros la violencia que una vez sufrió en el propio cuerpo. Para el autor, no hay buena violencia que pueda ser respuesta de la mala violencia, no se puede legitimar una sobre la otra.

El planteamiento mbembiano sobre la ontología del enemigo sigue la vía de los líderes, Martin Luther King, Nelson Mandela y Mahtatma Gandhi, héroes donde la respuesta violenta era la última de las alternativas. La política de la venganza no es otra cosa más que "la reproducción del complejo de Caín, no se puede imaginar un más allá de la destrucción y del resentimiento" (Mbembe, 2006b).

¿Qué debemos inventar primero? Mbembe responde: El cuerpo. 


\section{FUENTES CONSULTADAS}

Agamben, G. (1998). Homo Sacer, el poder soberano y la nuda vida. Valencia: Pre-Textos.

Benjamin, W. (1978 [1920]). Critique of Violence. En P. Demetz(Ed.), Reflections: Essays, Aphorisms, Autobiographical Writings. New York: Schocken Books.

Butler, J. (1997). The Psychic Life of Power: Theories of Subjection. Standford: Standford University Press.

Butler, J. (2004). Precarious Life: The Powers of Mourning and Violence. London and New York: Verso.

Butler, J. (2016). Los sentidos del sujeto. Barcelona: Herder.

Castro-Gómez, S. (2007). Michel Foucault y la colonialidad del poder. Revista Tabula Rasa, (6), 153-172. Recuperado desde http://www.redalyc.org/ pdf/396/39600607.pdf

Césaire, A. (1972). Discourse on Colonialism. New York: Monthly Review Press.

Chávez, H. (2013). Necropolítica. La política como trabajo de la muerte. Revista Ábaco, 4, 23-30. Recuperado desde http://www.revistasculturales.com/ xrevistas/PDF/72/1723.pdf

Deleuze, G., \& Guattari, F. (2006). Mil mesetas, Capitalismo y Esquizofrenia. Valencia: Pre-Textos.

Fanon, F. (1952). Black Skin, White Masks. París: Seuil.

Fanon, F. (2007 [1961]). Los Condenados de la Tierra. Buenos Aires: Fondo de Cultura Económica.

Fanon, F. (2011). Euvres. París: La Decouverte.

Foucault, M. (1979a). Microfisica del Poder. Madrid: La Piqueta.

Foucault, M. (2007 [1979b]). Nacimiento de la Biopolítica. Buenos Aires: Fondo de Cultura Económica.

Foucault, M. (1996a). Genealogía del racismo (Colección Caronte Ensayos). La Plata: Altamir.

Foucault, M. (1996b [1981]). Tecnologías del Yo y otros textos afines. Barcelona: Paidós.

Foucault, M. (2002a [1997]). Defender la sociedad. Curso en el Collège de France (1975-1976). México: Fondo de Cultura Económica.

Foucault, M. (2002b [1977]). Historia de la sexualidad. La voluntad del saber. Buenos Aires: Siglo XXI.

Gigena, A. (2011). Lecturas poscoloniales y decoloniales de la analítica foucaultiana para el análisis en contextos de herencia colonial. Confluenze, 3(2), 1-21. 
Recuperado desde https://confluenze.unibo.it/article/viewFile/2383/1779

Gilroy, P. (1995). The Black Atlantic. Cambridge: Harvard University Press

Gilroy, P. (2004). Postcolonial Melancholia. New York: Columbia University Press.

Grzinic, \& M. (2012). Biopolitics and Necropolitics in relation to the Lacanian four discourses. Paper presented at the Simposium Art and Research: Shared methodologies.Politics and Translation, Barcelona.

Hegel, F. (2006 [1807]). Fenomenología del Espíritu. Valencia: Pre-Textos

Kojève, A. (1982). La dialéctica del amo y del esclavo en Hegel . Buenos Aires: La Pléyade.

Lacan, J. (2005 [1975-1976]). Le Séminaire Livre XXIII, Le sinthome. París: Le Seuil.

Maldonado, N. (2008). La descolonización y el giro des-colonia. Tabula Rasa, (9), 61-72. Recuperado desde http://www.redalyc.org/pdf/396/39600905.pdf

Mbembe, A. (2000). De la Postcolonie. Essai sur l'imagination politique dans l'Afrique contemporaine. París: Karthala.

Mbembe, A. (2005). Sovereignty as a Form of Expenditure. En T. Blond \& F. Stepputat (Eds.), Sovereign Bodies: Citizens, Migrants and States in Postcolonial World. New York: Princeton University Press.

Mbembe, A. (2006a). Necropolítica. España: Mesulina.

Mbembe, A. (2006b). Qu'est-ce que la pensée postcoloniale? Esprit. Recuperado desde http:/www.esprit.presse.fr/article/mbembe-achille/qu-est-ce-quela-pensee-postcoloniale-entretien-13807? folder $=2$

Mbembe, A. (2008) What is postcolonial thinking?/ Entrevistador: Esprit. Eurozine. Recuperado desde http:/www.eurozine.com/what-is-postcolonial-thinking/

Mbembe, A. (2010a). 2010 Soccer World Cup: Where is the moral argument? Africultures. Les mondes en relation. Recuperado desde http://africultures. com/2010-soccer-world-cup-where-is-the-moral-argument-5757/

Mbembe, A. (2010b). Sortir de la grande nuit. Essai sur l'Afrique décolonisée. París: La Découverte.

Mbembe, A. (2011). Fanon's Nightmare, our Reality. Mail \& Guardian. Recuperado desde https://mg.co.za/article/2011-12-23-fanonsnightmare-our-reality

Mbembe, A. (2012). Necropolítica, una revisión crítica. En H. Chávez \& E. Jesik (Eds.), Estética y Violencia: necropolítica, militarización y vidas lloradas. México: Museo Universitario Arte Contemporáneo/Universidad Nacional Autónoma de México.

Mbembe, A. (2013a). Critique de la raison nègre. París: La Découverte. 
Mbembe,A. (2013b) Le Nègre, figure de l'émancipation humaine/Entrevistadora: R. Moussaoui. L'Humanité, Francia. Recuperado desde https://humanite. $\mathrm{fr} /$ monde/achille-mbembe-le-negre-figure-de-1-emancipation-h-554877

Mbembe, A. (2013c). Nelson Mandela, les chemins inattendus. Le Monde Diplomatique. Recuperado desde https://www.monde-diplomatique. fr/2013/08/MBEMBE/49518

Mbembe, A. (2016a) La France peine à entrer dans le monde qui vient/ Entrevistador: S. Faure \& C. Daumas. Libération. Recuperado desde http://www.liberation.fr/debats/2016/06/01/achille-mbembe-la-francepeine-a-entrer-dans-le-monde-qui-vient_1456698

Mbembe, A. (2016b) Le désir d'ennemi n'a jamais été aussi fort qu'en ce début de siècle /Entrevistadora: J. Cerf. Telérema.fr. Recuperado desde http:// www.telerama.fr/idees/achille-mbembe-le-desir-d-ennemi-n-a-jamais-eteaussi-fort-qu-en-ce-debut-de-siecle,142376.php

Mbembe, A. (2016c). Politiques de l'inimitié. París: La Découverte.

Mbembe, A. (2016d). The Society of Enmity. Radical Philosophy. Philosophical Journal of the Independent Left. Recuperado desde https://www. radicalphilosophy.com/article/the-society-of-enmity

Mignolo, W. (1995). The Darker Side of the Renaissance. Ann Arbor: The University of Michigan Press.

Nandy, A. (1983). The Intimate Enemy. Loss and Recovery of Self under Colonialism. In. Delhi: Oxford University Press.

Rivas, P., \& Madorrán, J. (2010). Sudáfrica. El perdón como motor de la historia. Nuestro tiempo. Revista cultural y de cuestiones actuales, (644). Recuperado desde http:/www.unav.es/nuestrotiempo/es/temas/sudafricael-perdon-como-motor-de-la-historia

Said, E. (1978). Orientalism. New York: Pantheon Books.

Spivak, C. (2003). ¿Puede hablar el subalterno? Revista Colombiana de Antropología, 39, 297-364. Recuperado desde https:// antropologiadeoutraforma.files.wordpress.com/2013/04/spivak-puede-elsubalterno-hablar.pdf

Tlostanova, M. (2011). From Biopolítics and necropolitics to geo-politics and body politics knowledge. RUDN Journal of Philosophy, (1), 39-47. Retrieved from http://journals.rudn.ru/philosophy/article/view/11342/10772

Žižek, S. (2005) Against human rights. New Left Review, Londres. Recuperado desde https://newleftreview.org/II/34/slavoj-zizek-against-human-rights 